\title{
Review on Analytical Design, Simulation, Fabrication, Characterization, and Packaging Aspects of Micro Electro Mechanical Switches for Radio Frequency Applications
}

\author{
K. Srinivasa Rao ${ }^{1 *}$, Lakshmi Narayana Thalluri ${ }^{1}$
}

${ }^{1}$ Professor \& Head of Microelectronics Research Group, Department of ECE, KL University, Green Fields, Vaddeswaram-522502, Guntur, A.P, India

${ }^{2}$ Research Scholar, Department of ECE, KL University, \& Assistant professor, Department of ECE, ALIET, Andhra Pradesh, India

Received: July 19, 2016; Accepted: July 26, 2016; Published: August 05, 2016

*Corresponding author: K. Srinivasa Rao, Professor and Head of Microelectronics Research Group, Department of ECE, KL University, Green Fields, Vaddeswaram-522502, Guntur, A.P, India, Email: drksrao@kluniversity.in

\begin{abstract}
This paper mainly reviews the Analytical Design, Simulation, Fabrication, Characterization, and Packaging aspects of Micro Electro Mechanical Switches for Radio Frequency Applications. The switching is mainly required in many applications i.e., in low frequency and high frequency applications. GaAs based PIN Diode and CMOS based FET are suitable for switching in low frequency applications, but for good isolation and insertion based switching in radio frequency these switches are not suitable. Radio Frequency Micro Electro Mechanical Switches are giving solution for this problem. In this paper, all verities of Radio Frequency MEMS switch merits and demerits are discussed. In addition to review, a cantilever based RF MEMS Switch is designed and simulated using Finite Element Method (FEM) tool. And a review based surface and bulk micromachining based fabrication processes discussed by correlating with the design and simulation aspects. Finally discussed about the challenges in the realization.
\end{abstract}

Keywords: Mems; Radio frequency; Switching; Cantilever; Beam; Electrostatic force; Material science

\section{Introduction}

By taking the initiation from the lecture "There's Plenty of Room at Bottom" is by Richard Feynman in 1959, a lot of research is forwarded in the Micro and NANO devices fabrication till the date. But still there is a scope of research in this area. The Micro and Nano elements are mainly fabricated using GaAs, CMOS, and MEMS technology. GaAs and CMOS technology elements are easy to fabricate and reliability is high, but in particular high frequency applications these technology based elements performance is poor. But MEMS technology based elements are giving good performance especially at high frequency. Not only for high frequency applications, had MEMS technology based elements providing high performance in different applications and different areas when compared to other technologies like GaAs, CMOS. This paper mainly reviews the design, fabrication, characterization, and packaging of Radio Frequency MEMS Switches. MEMS switches use some mechanical movement to achieve a closed or open circuit in the Radio Frequency transmission lines [1]. RF MEMS switches are the specific micromechanical switches that are designed to operate at $\mathrm{RF}$ - to - millimeter - wave frequencies ( 0.1 to $100 \mathrm{GHz}$ ) [1]. Upstate capacitance is sensitive to the power of RF signal generates nonlinear effects. Nonlinear effects like Inter Modulation (IM) are negligible in MEMS devices compared to other switching components like P-i-n diode, FET Transistor or tuning elements like Varactor diode, ferroelectric thin films [2].

GaAs FET switches do not have sufficient isolations to minimize cross interference and signal jamming from channels is close proximity. Pin diode require considerable power for operate. MEMS switches provide high isolation when isolation loss when open, low insertion loss when closed, and can be operated at low power consumption [3]. The performance of MEMS is good in Radio Frequency [3]. RF MEMS and waveguide technology constitute a very promising solution, since they allow for very high $\mathrm{Q}$ and good tunability. They employ tunable components (e.g. varactor diodes) and have the advantage to be very compact, but exhibit unloaded Qs below 100 [4]. MEMS switches provide high isolation, which is required in Base stations and satellite systems [5].

RF MEMS Switches classification depends on type of actuation, deflection axis, contact type, circuit configuration, and Structure configuration (Figure 1).

This paper discusses about electrostatically actuated fixedto-fixed bridge base capacitive and resistive type switches, cantilever based capacitive and resistive switches Shown in the figure. In electrostatically actuated switches the type of forces effects the deformation of the beam are classified as static forces (spring, Electrostatic, Contact force) and dynamic forces (Damping, Inertial force). Electrostatically actuated switches

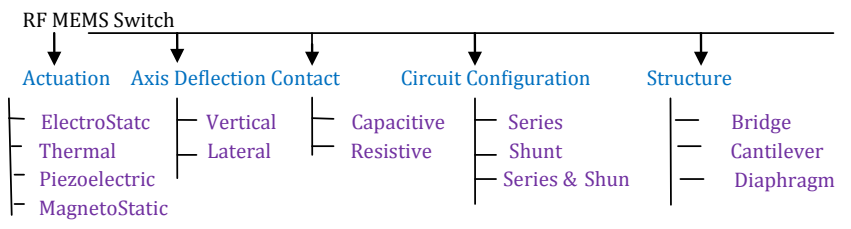

Figure 1: Classification of RF MEMS Switches. 
do not effectively consume dc power like electro thermal, but they suffer stiction and dielectric charging problems. Thermal actuators are not sensitive to those problems [6]. Stiction is because of two reasons one is due electrical behavior i.e. charge tapping and the other reason is due to mechanical behavior i.e. Creep and viscoelastic relaxation [7] (Figure 2).

Fixed-Fixed Beam switch is generally known as shunt switch, and cantilever beam based switches are generally known as series switches. The shunt capacitive switches will provide more than $-20 \mathrm{~dB}$ isolation at $10-50 \mathrm{GHz}$ in down state, and -0.04 to -0.1 $\mathrm{dB}$ insertion loss at $5-50 \mathrm{GHz}$ in upstate.

\section{Theoretical Analysis}

The RF MEMS Switches are theoretically analyzed and characterized with the help of some mechanical and electrical properties. In this paper all the properties are discussed by considering beam in the switch is rectangular in shape. Mainly in this section all the parameters are invoked by taking the two types of mechanical switches one is fixed-fixed bridge based and other one is cantilever based as shown in (Figure 3).

Where: l- Length; $w$ - Width; $t$ - Thickness; $t_{d}$ - Dielectric thickness; $\mathrm{g}_{0}$ - Gap between electrodes; W-Width of electrode

\section{Mechanical properties}

Analyzing the Elastic nature of a beam in the structure mainly comes in mechanical characterization of RF MEMS Switches. So, Hooke's law is origin for mechanical characterization. The mechanical properties are:

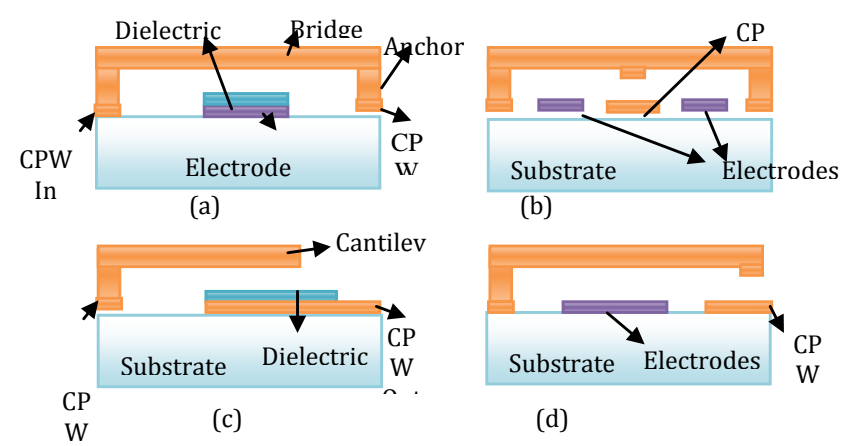

Figure 2: RF MEMS Shunt and Series Switches (a) Capacitive Shunt, (b) Resistive Shunt, (c) Capacitive Series, (d) Resistive Series.

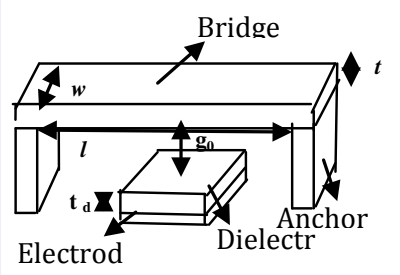

(a)

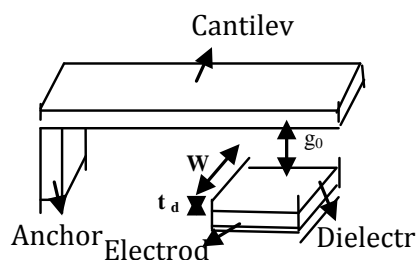

(b)
Figure 3: Capacitive Switches (a) Fixed-Fixed Bridge Switch (b) Cantilever Switch.
1. Mass (M): The mass of the beam is defined as the product of area $\left(l^{*} w^{*} t\right)$ and density $(\rho)$.

Beam Mass $(\mathrm{m})=\mathrm{l}^{*} \mathrm{w}^{*} \mathrm{t}^{*} \rho$

2. Stress $(\boldsymbol{\sigma})$ : It is defined as the ratio of applied force(F) to area (A) units are in $\mathrm{N} / \mathrm{m}^{2}$ i.e.,

Stress $(\sigma)=\mathrm{F} / \mathrm{A}$

3. Strain( $(\varepsilon)$ : After applying some load the beam will deform,stain is used to measure the deformation factor. It is the ratio of deformed length $(\Delta)$ to original length of beam (l) and it is constant.

Strain $(\varepsilon)=\Delta \mathrm{l} / \mathrm{l}$

4. Elastic Modulus (E): It is derived from Stress $(\sigma)$ and $\operatorname{strain}(\varepsilon)$ values, expessed as

Elastic Modulus $(\mathrm{E})=\sigma / \varepsilon$

5. Area Moment of Inertia(I): In this paper all the theoritical equations are derived by considering the the beam structure is rectangular in shape. And the moment of inertia for rectangular beam is given as

Area Moment of Inertia (I) $=\left(t^{3} w\right) / 12$

6. Deflection $(\boldsymbol{\delta})$ : When a significant force is applied on the structur there is defenetly a noticeble deformation will occure in the structure, to measure the deformation deflection is helpful and for rectangular cantilever it is given as

Deflection $(\delta)=\left(\mathrm{ql}^{4}\right) /(8 \mathrm{EI}) \quad(6.1)$

7. For a rectangular fixed-fixed beam the deflection is formulated as.

$$
\text { Deflection }(\delta)=\left(5 \mathrm{ql}^{4}\right) /(384 \mathrm{EI})(6.2)
$$

In both the cases, the uniformly distributed load (q) is applied on the structures.

1. Stiffness or Spring Constant (K): From the Hooke's Law it is clear that the required force for deformation is proportional to the spring constant i.e. if the spring constant is high means the pulls in voltage require is also high. So, it is better to choose the bridge material which has low spring constant.

Stiffness $(\mathrm{K})=\left(2 \mathrm{EWt^{3 }}\right) /\left(3 \mathrm{I}^{3}\right)$

2. Natural Resonant Frequency $(\omega)$ : the maximum ocillations the structure can do per unit time when a force is applied is known as natual resonant frequency. It is proportinal to siffness of the structure and inversely prportional to the mass of the structure. It is expreed as

$\sqrt{\frac{K}{m}}$

3. Switching Time $\left(\mathrm{t}_{\mathrm{s}}\right)$ : the minimum time taken by the switch to complete one cycle is known as switching time, 
in RF MEMS Switch it completely depends on pull in voltage $\left(\mathrm{V}_{\mathrm{p}}\right)$, Applied Voltage $\left(\mathrm{V}_{\mathrm{s}}\right)$ and is formulated as

$$
3.67\left(\mathrm{~V}_{\mathrm{p}} / \mathrm{V}_{\mathrm{s}} \boldsymbol{\omega}_{0}\right)
$$

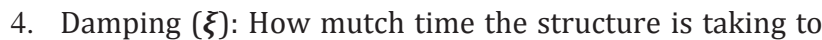
come to stability can be conclude using damping. If $\xi=0$ the structure will take more time to achive stability, elseif $\xi=1.5$ stability is achived quickly by the structure. The general damping is formulated as

$$
\frac{b}{2 \sqrt{K m}}
$$

Where: b-Damping Coefficient

5. Quality Factor: The quality factor is one of the important parameter of RF MEMS Switch and can be explained as the ratio of the energy stored to the energy dissipated per cycle at the resonant frequency. High Q indicates a lower rate of energy loss relative to the stored energy of the resonant circuit.

Quality Factor $(\mathrm{Q})=\mathrm{K} / \mathrm{b}_{0}$

Electrical Properties: This paper mainly discuss the electrostatic based switches, so the main electrical properties listed below

1. Electrostatic force: when a significant voltage is applied in between electrodes some electrostatic force will create and it can be expressed as

$$
\frac{1}{2} \frac{\varepsilon_{0} \mathrm{AV}^{2}}{\left(g_{0}+\frac{t_{d}}{\varepsilon r}-\delta\right)^{2}}
$$

2. Pull-in Voltage: The basic principle of electrostatic RF MEMS Switch is, some amount of voltage need to apply to get the deformation in the beam for switching. And for the recangular bassed beams the expected pull-in voltage is

$$
\sqrt{\frac{8 K}{27 A \varepsilon_{0}} g_{0}\left(\frac{t_{d}}{\varepsilon_{r}}\right)^{3}}
$$

3. Pull-up Voltage: After applying the pull in voltage the beam will deforms and because of elastic property of the beam it will try to get the stability. At waht voltage level the bram try to get the initial position is said to be pull up voltage.and the pull up voltage is formulated as

$$
\sqrt{\frac{2 K}{A \varepsilon_{0}} g_{0}\left(\frac{t_{d}}{\varepsilon_{r}}\right)^{2}}
$$

4. Capacitance: The capaciatnce in RF MEMS Switches is divided as Upstate capacitance and downstate capacitance.

The bridge based capacitive type switch has the Upstate Capacitance $\left(C_{u}\right)=C_{p}+C_{p p}+C_{f}$, and Down State Capacitance $\left(C_{d}\right)$ $=\mathrm{C}_{\mathrm{p}}+1.5 \mathrm{C}_{\mathrm{pp}}+\mathrm{C}_{\mathrm{f}}$, where $\mathrm{C}_{\mathrm{p}}$-Parasitic capacitance, $\mathrm{C}_{\mathrm{pp}}-$ Parallel plate
Capacitance $\left(\boldsymbol{\varepsilon}_{0} \mathrm{Ww} / \mathrm{g}_{0}\right)$, and $\mathrm{C}_{\mathrm{f}}$ - Fringing Field Capacitance. Fringing field capacitance which is around $10 \%-20 \%$ of $\mathrm{C}_{\mathrm{pp}}$ where: $\varepsilon_{0}$-Free space permittivity $=8.854 \times 10^{-12} \mathrm{~F} / \mathrm{m} \mathrm{[2]}$.

\section{Design and simulation aspects}

Finite Element Method (FEM) tools are very helpful to design and simulate the RF MESM Switches. Comsol Multiphysics, Coventorware, Intellisuite are the well-known FEM Tools. In this paper as an example, an electrostatic actuated, lateral deflective, bridge based, series capacitive RF MEMS Switch is designed and simulated using Comsol Multiphysics FEM tool.

As shown in the (figure 4), a cantilever based switch with geometrical dimensions length $\mathrm{l}=90 \mu \mathrm{m}$, width $\mathrm{w}=20 \mu \mathrm{m}$, thickness $\mathrm{t}=1 \mu \mathrm{m}$, gap between the electrodes $\mathrm{g}_{0}=0.1 \mu \mathrm{m}$. and the dielectric thickness $t_{d}=0.9 \mu \mathrm{m}$ and the width of the bottom electrode $\mathrm{W}=20 \mu \mathrm{m}$. Gold $(\mathrm{Au})$ is used as a cantilever material, and Silicon Nitride $\left(\mathrm{Si}_{3} \mathrm{~N}_{4}\right)$ with dielectric constant 7.5 is used as dielectric material. And the working principle of the switch is, initially the input applied voltage is $1 \mathrm{mv}$ there is no deformation in the switch under this condition input is equal to output, but the second case in addition a $5 \mathrm{v}$ is added to $1 \mathrm{mv}$ then there is some electrostatic force is created between the electrodes then the cantilever will deform and touches to ground under this condition the output is zero.

With the above mentioned dimensions and working principle an electrostatically actuated capacitive switch is designed and simulated using Comsol Multiphysics FEM tool, the results are shown in (Figure 5).

\section{Fabrication processes}

The micro fabrication from top to bottom involves different important processes, and are listed below

A. Material Selection:

1) Wafer: Most of the MEMS devices fabrication takes the substrate as silicon, GaAs, Quartz, as active substrates and polymers, Plastic, Ceramics, are as passive substrates.

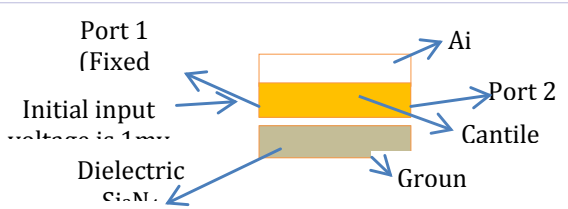

(a)

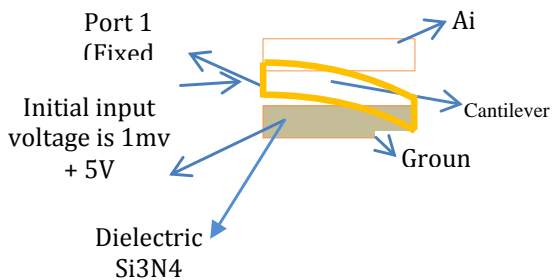

Figure 4: Electrostatic Deflection in cantilever (a) Applied Voltage is $1 \mathrm{mv}$ (Zero Deformation) (b) Applied Voltage is $1 \mathrm{mv}+5 \mathrm{v}$ (Significant deformation) 
Additionally LaAlO3 [8] can be used as substates.

2) Beam: The frequently used materials as membrane are Gold( $\mathrm{Au})$, Aluminum( $\mathrm{Al})$, polymers. From list polymers are preferable because of their light weight the pull-in voltage can be minimize.

3) Dielectric: Silicon Dioxide( $\left(\mathrm{Sio}_{2}\right)$, Silicon Nitride $\left(\mathrm{Si}_{3} \mathrm{~N}_{4}\right)$, Polymethyle Methacrylate (PMMA).

4) Sacrificial Layer: the material used as sacrificial layer must and should consist some mechanical properties like adhesion and low residual stress to avoid failures in the switch. So the selection of structural material and the sacrificial layer combination is very important. Few combinations are shown in (Table 1).

a. Cleaning: After completion of each fabrication step followed by there is cleaning process will present to remove dust particles. Piranha cleaning is famous for wafer cleaning after completion of each step.

b. Piranha Cleaning: The combinaation of sulfuric acid $\left(\mathrm{H}_{2} \mathrm{SO}_{4}\right)$ :Hydrogen peraxide $\left(\mathrm{H}_{2} \mathrm{O}_{2}\right)$ is used as cleaning solution for wafer and some tiems used to remove photoresist.

C. Masks preparation:Generally RF MEMS Switch fabrication require transmission layer mask, dielectric mask, sacrificial layer mask, beam or membrane mask, overall minimum four masks require for lithography [8].

d. Photo Lithography: This process is used to remove the unwanted portion from the deposited film. In this process fist a photoresist layer is uniformly formed on the surface of the film with the help of spin coater. Generally PMMA, PMGI are used as photoresist material. Next UV light is projected on the photoresist through a mask, and after by using developers the exposed (Positive) or unexposed (negative) photoresist is removed by using different developers as shown in (Figure 6).

e. E. UV Light: Generally PMMA, PMGI, DQN are used as positive photoresist and Bis (aryl)azide rubber, KTRF are used as negative resist materials. Positive resist materials are more sensitive to UV light, and negative resist materials are more sensitive to electron beam.

f. Deposition Techniques:In micro fabrication, different type of materials like semicondutors, metals, poly silicon, dielectrics need to diposit on the wafers for that there different dipocition techniques are available. The diposition techniques are classification is shown in the (Table 2).

g. Etching: Removal of specified portion with the help of chemicals or gases is known as etching in micro fabrication process. Etching processes classification is shown in the (Table 3).

\section{Fabrication methods}

To fabricate MEMS Based RF Switches there are deferent Micromachining methods. They are elaborated below,

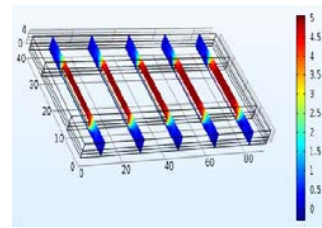

(a)

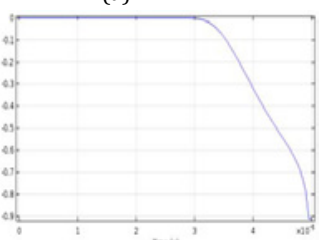

(c)

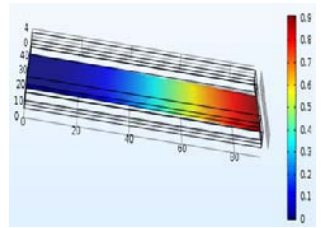

(b)

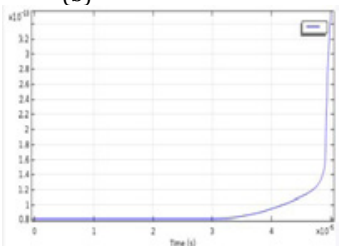

(d)
Figure 5: Design \& Simulation of Cantilever Switch (a) Potential Applied, (b) Cantilever Deformed, (c) Deflection Graph, (d)Capacitance Graph.

\begin{tabular}{|l|l|}
\hline Table 1: Material and suitable sacrificial layers. \\
\hline Structural Material & Sacrificial Material \\
\hline Poly Silicon, Gold, Aluminum, etc. & $\mathrm{SiO}_{2}$, Phosphosilicate Glass (PSG) \\
\hline
\end{tabular}

\section{$\downarrow \downarrow \downarrow \downarrow \downarrow \downarrow \downarrow \downarrow \downarrow$}

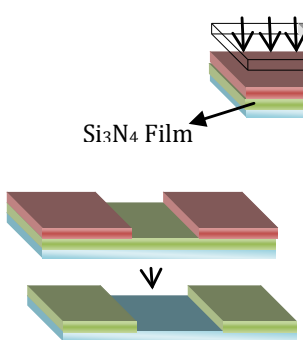

(b)
Figure 6: (a) UV Lithography (b) Positive Photoresist (c) Negative Photoresist.

Table 2: Classification of Film Deposition Techniques.

\begin{tabular}{|l|l|l|l|}
\hline \multicolumn{4}{|c|}{ Deposition Techniques } \\
\hline $\begin{array}{l}\text { Thermal } \\
\text { Oxidation }\end{array}$ & $\begin{array}{l}\text { Physical Vapor } \\
\text { Deposition }\end{array}$ & $\begin{array}{l}\text { Chemical } \\
\text { Vapor } \\
\text { Deposition }\end{array}$ & Others \\
\hline - Wet Oxidation & - Evaporation & -PECVD & -Electroplating \\
- Dry Oxidation & -APCVD & $\begin{array}{l}\text { (Thermal / E-Beam) } \\
\text { - Sputtering (DC / RF) }\end{array}$ & $\begin{array}{l}\text {-LPCVD } \\
\text {-MOCVD }\end{array}$ \\
\hline
\end{tabular}

B. Bulk Micromachining: In bulk micromachining the entire structure of the element is created in the substrate as shown in the (Figure 7).

Cantilev: In this section the fabrication of $\mathrm{a} \mathrm{SiO}_{2}$ cantilever on silicon wafer using bulk micromachining is explained.

(a) As the basic step, the wafer is cleaned using piranha 
solution $\left(\mathrm{H}_{2} \mathrm{SO}_{4}: \mathrm{H}_{2} \mathrm{O}_{2}\right.$ in 9:1 ratio) to remove the organic and chemical contaminations on the wafer surface, rinse with DI water and blower with nitrogen. After cleaning the wafer samples are forwarded to thermal oxidation to form the $\mathrm{SiO}_{2}$ on the Silicon wafer surface. As the next step in photolithography, first the samples are dehydrated at $250^{\circ} \mathrm{C}$ for 10 minutes. Next a photoresist (PMMA) is formed on the surface of the samples by using a spin coater with $4000 \mathrm{rpm}$ for $10 \mathrm{sec}$. Soft baking is the intermediate process of keeping the samples at $95^{\circ} \mathrm{C}$ for 2 minutes to evaporate the solvents in the photoresist. (b) And next UV light is exposure through a cantilever mask for 2 sec. (c) After UV exposure the samples are placed in a special developing solution $(\mathrm{NAOH})$ which will dissolve the exposed photoresist, rinse with DI water and blower with nitrogen processes will follow. (d) Now the exposed $\mathrm{SiO}_{2}$ is removed using BHF based wet etching. (e) Acetone Solution is used to remove the leftover photoresist and again the piranha cleaning using $\mathrm{H}_{2} \mathrm{SO}_{4}: \mathrm{H}_{2} \mathrm{O}_{2}$ in $3: 1$ ratio, DI water clean nitrogen blow is done to remove the dust particles. (f) Next the exposed silicon is etched isotropic ally using $\mathrm{KOH}$.

J. Surface Micromachining: In surface micromachining the entire structure of the element is created on the top of the substrate as shown in the (Figure 9).

h. Cantilev: In this section the patterning of a simple Silicon cantilever beam using Silicon on Insulator (SOI) wafer by following surface micromachining process is explained.

(a) As the basic step, the SOI is cleaned using piranha solution $\left(\mathrm{H}_{2} \mathrm{SO}_{4}: \mathrm{H}_{2} \mathrm{O}_{2}\right.$ in 9:1 ratio) to remove the organic and chemical contaminations on the wafer surface, rinse with DI water and blower with nitrogen. A Positive Photoresist Material (PMMA) is formed on the surface of the SOI by using a spin coater with $4000 \mathrm{rpm}$ for $10 \mathrm{sec}$. Soft baking is the intermediate process of keeping the samples at $95^{\circ} \mathrm{C}$ for 2 minutes to evaporate the solvents in the photoresist. (b) Next the coated SOI is forwarded to photolithography; here first the samples are dehydrated at $250^{\circ} \mathrm{C}$ for 10 minutes and UV light is exposure through a cantilever mask for $2 \mathrm{sec}$. (c) After UV exposure the samples are placed in a special developing solution (NAOH) which will dissolve the exposed photoresist, rinse with DI water and blower with nitrogen processes will follow. (d) Now the exposed Si is removed using dry etching like anisotropic plasma etching. (e) Piranha cleaning to remove the leftover photoresist using $\mathrm{H}_{2} \mathrm{SO}_{4}: \mathrm{H}_{2} \mathrm{O}_{2}$ in $3: 1$ ratio, DI water clean nitrogen blow is done to remove the dust particles. In the cleaning process petri dishes are used to carry the solutions. (f) Next the samples are place in wet etch $\mathrm{BHF}$ solution to remove the exposed $\mathrm{SiO}_{2}$ and to release the cantilever. Finally the samples are dried up to critical point to avoid the stiction and to prevent the structural collapse.

i. UV Light: Alternatively there exist one more fabrication method i.e. LIGA Process, but it is costly and complex compared to Surface and bulk micromachining processes.

\section{Characterization}

After fabrication to improve the reliability characterization is important. Microscopes are used to characterize the Micro and Nano devices. General microscopes used to characterize the micro and Nano elements materials are Optical microscope,
Table 3: Classification of Etching Processes.

\begin{tabular}{|l|l|}
\hline & \multicolumn{2}{|c|}{ Etching Processes } \\
\hline & Dry Etching \\
\hline - Immersion Etching & - Plasma Etching \\
- Spray Etching & - Sputtering \\
& - Reactive Ion Etching (RIE) \\
& - IBE \\
& - RIBE \\
\hline
\end{tabular}

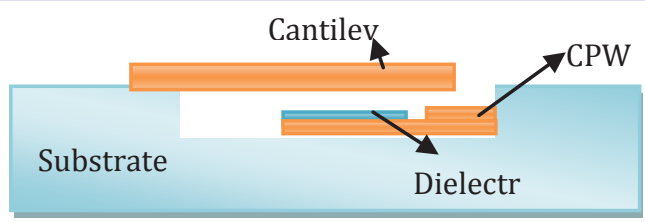

Figure 7: Bulk Micromachining (Example Structure)

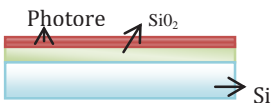

(a)

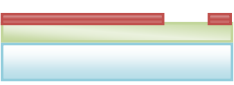

(c)

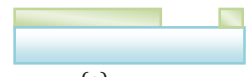

(e)

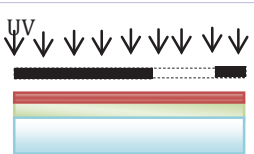

(b)

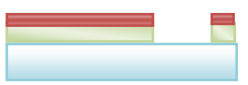

(d)

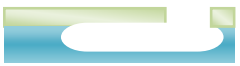

(f)
Figure 8: Cantilever pattern Steps using Bulk Micromachining.

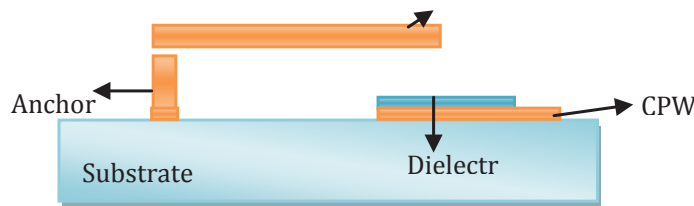

Figure 9: Surface Micromachining (Example Structure)

UV Light

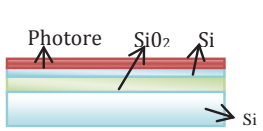

(a)

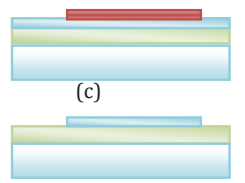

(e)

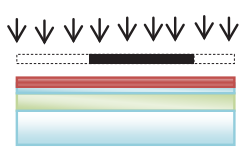

(b)

(d)

(f)

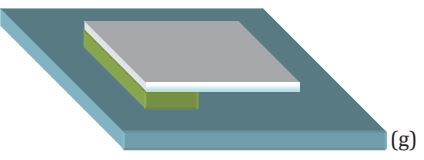

Figure 10: Cantilever patterning on SOI Steps using Surface Micromachining 
Field Emission Scanning Microscope (FESM), Scanning Electron Microscope (SEM), Tunneling Electron Microscope (TEM), and Atomic Force Microscope (AFM). Finally the structure frequency is characterized by applying some voltage using Laser Doppler Vibrometer (LDV). The Micro \& NANO devices can characterize by finding device materials surface properties, device input impedance, practical reliability, and estimation of lifetime.

\section{Packaging}

Hermetic packaging is used for RF MEMS Packaging because the devices are more sensitive. Seam, Roller or Laser sealing are used in hermetic packaging which is composed of materials like ceramic, beryllium oxide, aluminum, Aluminum Nitride. The packaging of RF MEMS Switches is most expensive it is around $30 \$-50 \$$ per unit. Packaging costs are currently high, and the packaging technique itself may adversely affect the reliability of the MEMS switch [1]. Improving the yield of MEMS device after packaging. Even though the device could yield up to $90 \%$, after packaging, the yield could be as low as $20 \%$ [3].

\section{Challenges}

Last few decades, an excellent research is forwarded in the area of RF MEMS Switches still the challenges are showing the scope of research. Few important challenges in electrostatically actuated RF MEMS switches are, the switching speed of most MEMS switches is around 2-40 $\mu$ s. Certain communication and radar systems require much faster switches. Most MEMS switches cannot handle more than 20-50 mW. MEMS switches that handle $0.2-10 \mathrm{~W}$ with high reliability simply do not exist today. Electrostatic MEMS switches require 20-80 V for reliable operation, and this necessitates a voltage up-converter chip when used in portable telecommunication systems. The reliability of mature MEMS switches is $0.1-10$ billion cycles. However, many systems require switches with 20-200 billion cycles. Also, the long-term reliability (years) has not yet been addressed. MEMS switches need to be packaged in inert atmospheres (nitrogen, argon, etc.) and in very low humidity, resulting in hermetic or near-hermetic seals. Packaging costs are currently high, and the packaging technique itself may adversely effect the reliability of the MEMS switch [1]. Improving the yield of MEMS device after packaging. Even though the device could yield up to $90 \%$, after packaging, the yield could be as low as 20\% [3]. MEMS Devices are operated at $1-100 \mathrm{mw}$, so linearity is a critical parameter to prevent distortion or inter channel interference [2]. Alleviate the stiction phenomenon significantly increasing the device lifetime [7]. Reliability of MEMS is a real challenge, narrowing of the actuation and release voltages during long period of continuous actuation [7]. Electrostatically actuated switches do not effectively consume dc power; they suffer stiction and dielectric charging problems due to humidity [9]. Thermal actuators are not sensitive to those problems [6]. At higher temperatures the beam stress becomes compressive and leads to buckling of the beam and device failure [10]. Typical reliability problems of the contact type switches are listed in (Table 4) [11].

\section{Conclusion}

This paper reviewed the merits and demerits in the realization of different RF MEMS Switches. In the review, major challenges are noticed at different levels of realization. Based on the review, for high frequency applications prefer capacitive shunt switches and for low frequency applications prefer the series resistive switches. The main challenge in the RF MEMS Switches is more pull-in voltage, to reduce the pullin voltage the structure must be light weight and more elastic for that polymers are the best materials as a cantilever. To fabricate the switch, both surface and bulk micromachining are giving good results,

\begin{tabular}{|l|l|}
\hline Table 4: Contact Type Switch Reliability Problems. \\
\hline Switch Type & Problems \\
\hline $\begin{array}{l}\text { Metal Contact } \\
\text { Switch }\end{array}$ & $\begin{array}{l}\text { - Increasing Contact Resistance } \\
\text { - Microwelding Phenomenon }\end{array}$ \\
\hline $\begin{array}{l}\text { Capacitive } \\
\text { Coupling Switch }\end{array}$ & $\begin{array}{l}\text { - Stiction between the dielectric layer and the metal } \\
\text { - Charge injection and charge trapping in the } \\
\text { dielectric layer }\end{array}$ \\
\hline
\end{tabular}

and LIGA Process is much costly compared to Surface and Bulk micromachining. Packaging the switch is the biggest challenge, which is playing major role in the switch reliability.

Other than the packaging the major challenges are reduction of pull-in voltage, humidity and temperature tolerance, stiction, lifetime, Structure Viscoelastic Problems.

\section{References}

1. Gabriel M R, Jeremy B. M, RF MEMS Switches and Switch circuits. ISSN 1527-3342/01/\$10.00@; 2001. IEEE microwave magazine.

2. Laurent D, Member, Rebeiz G M. Intermodulation Distortion and Power Handling in RF MEMS Switches, Varactors, and Tunable Filters. ieee transactions on microwave theory and techniques. 2003; 51(4).

3. Mercado L L, Kuo S M, Lee T Y, Russell Lee. Analysis of RF MEMS Switch Packaging Process for Yield Improvement. IEEE transactions on advanced packaging. 2005;28(1).

4. Luca P, Fabrizio C, Paola F, Roberto S. High- Tunable Waveguide Filters Using Ohmic RF MEMS Switches. ieee transactions on microwave theory and techniques. 2015;63(10).

5. Muldavin J B, Rebeiz G M. All-Metal High-Isolation Series and Series/ Shunt MEMS Switches. IEEE Microwave and Wireless Components Letters. 2001;11(9).

6. Bakri-Kassem M, Mansour R R. High Power Latching RF MEMS Switches. ieee transactions on microwave theory and techniques. $2015 ; 63(1)$.

7. Barbato M, Gaudenzio M. A Novel Technique to Alleviate the Stiction Phenomenon in Radio Frequency Microelectromechanical Switches. IEEE electron device letters. 2015;36(2).

8. Hijazi Y S, Hanna D, Fairweather D, Vlasov Y A, Grover L L. Fabrication of a Superconducting MEM Shunt Switch for RF Applications. IEEE transactions on applied superconductivity. 2003;13(2).

9. Zhen P, Cristiano P, James C M H, David I F, Charles L G, Cody M, et al. Impact of Humidity on Dielectric Charging in RF MEMS Capacitive Switches. IEEE microwave and wireless components letters. 2009;19(5).

10.10 Kaan D, Erdem Y, Simsek D, Tayfun A. A New TemperatureTolerant RF MEMS Switch Structure Design and Fabrication for Ka-Band Applications. journal of microelectromechanical systems. 2016;25(1)

11. Jaehong P, Eun S S, Wooyeol C, Youngmin K, Youngwoo K, Dong-il C, A Non-Contact-Type RF MEMS Switch for 24-GHz Radar Applications. journal of microelectromechanical systems. 2009;18(1). 